\title{
Minireviews
}

\section{Etiopathogenesis and Pharmacological Prevention of a Type-2 Diabetes Model in Male Mice ${ }^{\mathbf{S}}$}

\author{
Alberto Loizzo, Santi M. Spampinato, Gabriele Campana, and Stefano Loizzo \\ National Center for Global Health, Istituto Superiore di Sanità, Roma, Italy (A.L., S.L.); and Department of Pharmacy and \\ Biotechnology, University of Bologna, Bologna, Italy (S.M.S., G.C.)
}

Received October 4, 2017; accepted November 15, 2017

\begin{abstract}
We describe a stress-derived type-2 diabetes model in male mice, and formulate new hypotheses on how the model was induced, how diabetes-like alterations were prevented through specific pharmacological treatments, and how its possible neuroendocrine pathogenesis could be hypothesized. Pregnant females arrived in our laboratory on their 14th day of conceptional age. After birth, control mice never showed any apparent behavioral-metabolic-endocrine alterations. However, application of postnatal stress (brief mother deprivation, plus sham injection, daily from birth to weaning), was followed in adult male mice by two series of diabetes-like alterations. Some alterations (e.g., body overweight, immune, neurophysiologic, neurobehavioral alterations) were selectively prevented by opioid antagonist naloxone daily administered during nursing period. The aforementioned alterations plus several others (e.g., hyperglycemia, neuroendocrine alterations) were prevented by administration of specific antisense oligodeoxinucleotide, which modulated synthesis-hyperfunction of
\end{abstract}

\section{Introduction}

Despite clinical and laboratory research, no concordance still exists on etiopathogenesis of type- 2 diabetes mellitus, even if genetic-epigenetic factors, preperinatal environment, and lifestyle play important roles (Hanson and Gluckman, 2014; Bouret et al., 2015; Barrès and Zierath, 2016). Epidemiologic investigations have found that adverse prenatal, as well as adverse early life experiences in children were connected to increased lifetime risk to develop chronic metabolic alterations, such as becoming overweight and developing type-2 diabetes (Barker, 1998; Thomas et al., 2008; Shonkoff et al., 2012; Jiang et al., 2013; Eriksson et al., 2014; Birnbaum

This work was funded by the intramural program of the National Institutes of Health Joint Research Project for Rare Diseases, and by the Project "Pediatric Pharmacology," from the Istituto Superiore di Sanita' (ISS).

The authors declare no conflict of interest.

https://doi.org/10.1124/jpet.117.244707.

S This article has supplemental material available at jpet.aspetjournals.org. proopiomelanocortin-derived corticotropin (ACTH)-corticosterone and endorphins in the pituitary. Surprisingly, together with metabolic alterations, enduring increment of neurophysiologic/neurobehavioral brain performances were observed, accompanied by energy compensative reactions, and brain mitochondria hyperfunction. Thus, increased glycemia/lipidemia appeared to furnish fuel necessary to cope with increased request of energy. Diabeteslike alterations were accompanied by enduring hyperfunction of opioid- and ACTH-corticosterone-endogenous structures in the brain, which were apparently due to failure of negative feedback hormone mechanisms in the pituitary, for the control of the hypothalamus-pituitary-adrenal axis. In conclusion, for the first time we can hypothesize that a diabetes-like syndrome is produced by enduring hyperfunction of two proopiomelanocortin-dependent endogenous systems (brain opioid- and ACTH-corticosterone systems), following failure of pituitary feedback hormonal control, after complex stress procedures.

ABBREVIATIONS: ACTH, corticotropin; $\mathrm{AS}$, antisense oligodeoxinucleotide; $\mathrm{CRH}$, corticotropin-releasing hormone; HPA, hypothalamus-pituitaryadrenal; HSD11B1, $11 \beta$-hydroxysteroid dehydrogenase type 1; HSD11B2, $11 \beta$-hydroxysteroid dehydrogenase type 2; PND, postnatal day; POMC, proopiomelanocortin. 
diabetes mellitus-like syndrome. Interestingly, also reactive changes in the hypothalamus came to the attention of researchers since these changes were shown to trigger leptin and insulin resistance also observed in prediabetes (Kälin et al., 2015). In the obesity and type-2 diabetes research fields, mouse models have proven invaluable in the basic science of diseases by identifying the roles of inflammation, insulin resistance, fat content of the diet, and potential treatments (Islam and Loots, 2009; Heydemann, 2016). However, pathogenetic mechanisms connecting early stress to metabolic diseases in humans and/or animal models are still matters of debate.

Here, we describe a reliable and reproducible model in male mice as a new approach to study the causes and evolution of type-2 diabetes-like syndrome in mice in order to better investigate its etiopathogenetic mechanisms and to develop drugs useful in the prevention or reduction of diabetes-like alterations and risk of complications in mice.

\section{The Animal Model}

Early Stress and Its Neurobehavioral-MetabolicHormonal Effects in Rodents. Pioneering investigations (Weininger, 1954; Levine, 1957; Denenberg and Karas, 1959) have shown that early repeated mild psychologic stress alone, such as handling/mother separation, daily applied to rodents at birth or thereafter produced upset of both behavioral and metabolic functions, accompanied by HPA-axis hormone disturbances. These investigations opened the way to a series of relevant observations addressed to study mainly psychophysiologic-behavioral consequences induced by postnatal psychologic stress to adult rodents, and their relationships to HPA-axis hormones (for references see Akil and Morano, 1995; Loizzo et al., 2010a; Oitzl et al., 2010). However, the other face of the coin, i.e., the metabolic consequences of early stress, was substantially neglected during the following three to four decades.

Prenatal and Neonatal Procedures of the Model. Our investigations were addressed to study mainly the other face of the coin, i.e., the metabolic alterations following early stress in male mice. Animal care, environmental conditions, and use followed the rules of the Council of European Communities 56/609/EEC, and "Principles of laboratory animal care" (National Institutes of Health publication No. 85-23, revised 1985). Experimental procedures were approved by the Bioethical Committee of the Italian Istituto Superiore di Sanità and by the Italian Ministry of Health. All efforts were made to minimize the number of animals and their suffering. A series of multiparous pregnant outbred CD-1 mice (Charles River Italia, Calco, Italy) arrived at day 14 of conceptional age in our vivarium, where animals were kept in single plastic cages. After birth, pups of equal body weight were grouped together, randomly culled to six male pups per nest, and randomly crossfostered (Loizzo et al., 2006). Starting from the second postnatal day (PND), we adopted the mother deprivation stress model, but with an additional stressful condition: we coupled the usual psychologic stress (10 minutes of mother deprivation) to a mild physical pain stress caused by a subcutaneous saline injection, contextually administered daily from birth to weaning, i.e., from 2 to 21 PND (Pieretti et al., 1991). In view of the influences exerted by the endogenous opioid system on several diabetes-like alterations induced by our model (see Prenatal and Neonatal Procedures of the Model), experiments were performed only during the winter period, in which maximal sensitivity of opioid receptors in mice was described (De Ceballos and De Felipe, 1984). After weaning, mice were caged in groups of three subjects belonging to the same treatment, and were left undisturbed in their cages, except for cage cleaning twice weekly, until experiments began (Table 1).

Reliability and repeatability of the model were tested through a reference protocol applied to a series of experimental animals in various experimental sessions over the last 25 years, which consisted of the following: 1) body weight recording, 2) nociceptive test (tail-flick/hot-plate) applied at 25-30 PND, and 3) fasting glycemia at euthanasia (usually at $90 \mathrm{PND}$, sometimes up to $140 \mathrm{PND})$. Other independent investigators have adopted the same model as ours, including prenatal travel stress, and found results quite identical to ours in their stressed mice (e.g., Valenzuela et al., 2011). Similar models adopted by other groups have produced similar results in rats (e.g., McPherson et al., 2009). We underline that changes in one or more experimental conditions may challenge the reliability of results (Supplemental Material).

Early Stress and the Endogenous Opioid System. Following the stress model, we observed a consistent increase in the nociceptive threshold in mice, and this effect was observed from $25 \mathrm{PND}$ at least up to $45 \mathrm{PND}$; moreover, stressed mice showed an increase in the body weight incremental curve over controls. The increase was significant after 60-80 PND, and was accompanied by an increase in abdominal fat weight (periepididymal fat pads), increased volume of abdominal fat cells, and lasted at least up to 135-140 PND (Pieretti et al., 1991; d'Amore et al., 1995; Loizzo et al., 2006, 2012a). In our model, these effects were prevented in a dose-dependent way by daily injection of naloxone (from 0.1 to $1 \mathrm{mg} \mathrm{kg}{ }^{-1}$ body weight, as the weight of the base, but in most experiments the $1 \mathrm{mg} \mathrm{kg}^{-1}$ dose was adopted) (Loizzo et al., 2012a) administered during the nursing period (not yet verified for fat cell volume). Therefore, we deduced that our stress model not only induced alteration of the HPA system, as has been described by several investigations following repeated perinatal stress (see Akil and Morano, 1995), but also induced consistent and prolonged upregulation of endogenous opioid system activity as well. Independent investigators from other laboratories have found that following the repeated brief mother deprivation model alone (no sham injection) enduring alteration of brain endogenous opioid peptide activity and/or opioid receptors was elicited in selected brain regions in rats (Irazusta et al., 1999; Ploj et al., 1999, 2003; Ploj and Nylander, 2003; Gustafsson et al., 2008; Kiosterakis et al., 2009).

Timing of Opioid and Corticosteroid Receptor Development. We applied our postnatal stress model during the nursing period (2-21 PND) because during this period several physiologic functions/receptors (in particular, corticosteroid and opioid receptors) pass through their critical developmental period in rodent brain, and have maximal sensitivity to stressful events; therefore, insults applied to mice and rats during this period may produce long-term or permanent alteration of receptor function (McDowell and Kitchen, 1987; Rosenfeld et al., 1993; Costa, 1993). We hypothesized that involvement of both receptor systems was necessary to explain etiopathogenesis of stress-related metabolic alterations, and that the acknowledged chain of hormone release elicited by our stress 
TABLE 1

Timing of experimental procedures

\begin{tabular}{|c|c|}
\hline Day & Timing/Experimental Procedure \\
\hline Day 7 from birth ${ }^{a}$ & Pregnant mothers are transferred from the factory to our institute. \\
\hline Day 1 of birth (PND1) & $\begin{array}{l}\text { Pups are culled to six male animals per nest and randomly cross- } \\
\text { fostered. }\end{array}$ \\
\hline Day 2 (PND2) & $\begin{array}{l}\text { Treatment starts for all groups receiving any drugs. Animals in the C } \\
\text { (control) groups are left undisturbed, except for cage cleaning twice } \\
\text { a week }\end{array}$ \\
\hline Day 21 (PND21) & $\begin{array}{l}\text { Treatment ends. Homogenous litters of animals are set in groups of } \\
\text { three per cage, weighed and weaned. Then, all animals are left } \\
\text { undisturbed. }\end{array}$ \\
\hline Day 30 (PND30) & $\begin{array}{l}\text { Animals are weighed and tested at the tail-flick/hot-plate } \\
\text { apparatuses. Other experimental procedures are performed at ages } \\
\text { indicated in figures } 3,4,5 \text {, and } 6 \text {. }\end{array}$ \\
\hline
\end{tabular}

${ }^{a}$ Day 14 of conceptional age.

model, i.e., corticotropin (ACTH)-releasing hormone $(\mathrm{CRH}) \rightarrow$ proopiomelanocortin (POMC) $\rightarrow$ ACTH plus $\beta$-endorphin (and possibly other hormones) played an important role as well. POMC is an important ring of the hormonal HPA chain since it gives rise to equimolecular amounts of ACTH and $\beta$-endorphin through cleavage mechanisms (Vale et al.,1981). Therefore, we addressed our investigations to explore physiologic/regulatory mechanisms that are at the basis of homeostasis/hyperactivity of both opioid and ACTH-corticosterone endogenous systems in order to understand the step-by-step trajectories from cause (stress) to effect (adult type-2 diabetes-like syndrome) in male mice (see The Neuroendocrine Basis of the Model).

\section{The Neuroendocrine Basis of the Model}

Following our stress model, mice showed several metabolic, behavioral, immunologic, and neuroendocrine alterations (Fig. 1; see also Figs. 3-6 and Supplemental Material) similar to those observed in human type- 2 diabetes and prediabetes
(Ferrannini, 2014) (Fig. 1). In our model, we studied mechanisms that can produce these alterations.

In normal animals, following a single acute stress, plasma ACTH and corticosterone levels increase abruptly. In the absence of further stimuli, this increase triggers specific feedback negative control mechanisms, and these hormones return to physiologic steady-state levels within minutes or hours (Akil and Morano, 1995; Hackett and Steptoe, 2017) (Fig. 2A). Conversely, in the case of repeated stressful stimuli, unexpected results may be produced: following daily stress through the nursing period, our stressed male mice at age 90 PND and thereafter, i.e., at least 70 days after the end of stress, still showed enduring abnormal enhancement of plasma and pituitary ACTH, and consequently showed enhancement of corticosterone plasma levels. At the same time, $\mathrm{CRH}$ and ACTH levels in the hypothalamus were strongly reduced in stressed mice versus controls, as expected (Fig. 2, B and C) (Galietta et al., 2006; Loizzo et al., 2010a). Therefore, we argued that hypothalamic feedback negative mechanisms for the control of $\mathrm{CRH}$ and ACTH levels were

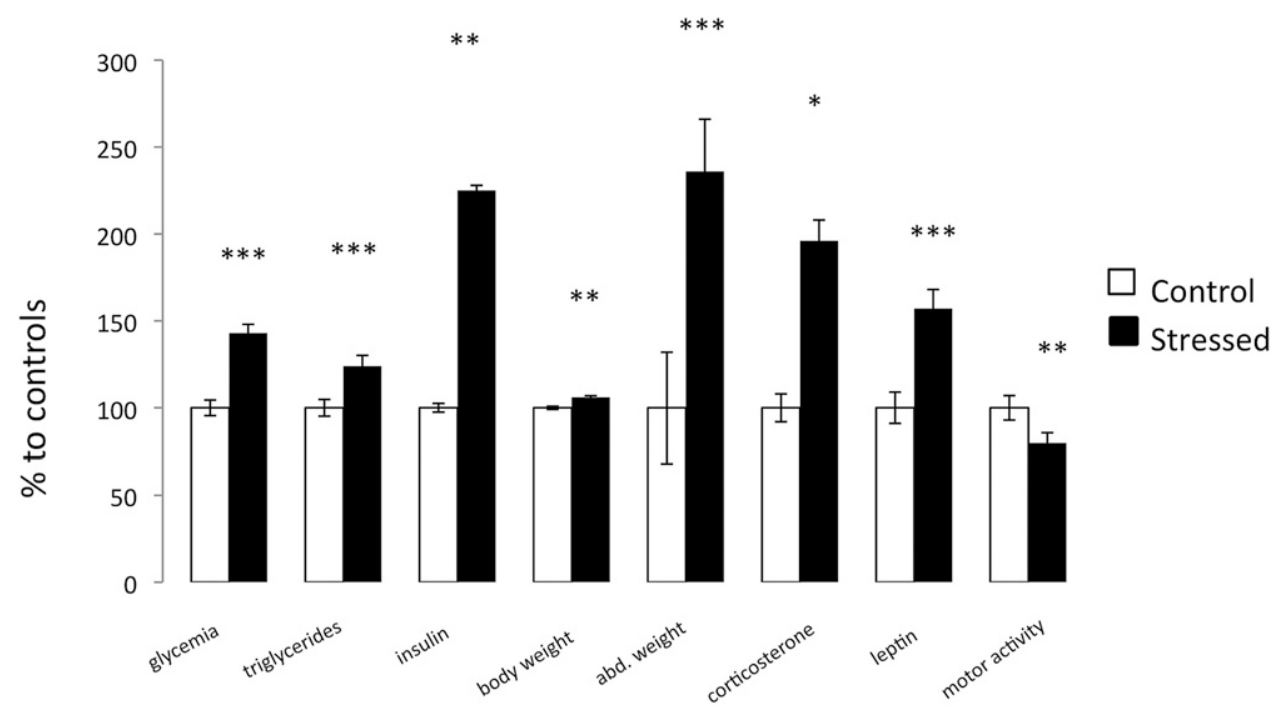

Fig. 1. Main diabetes-like effects induced by stress. Data are expressed in percentage vs. controls, \pm S.E.M. Data in control mice at about 90 PND were: fasting glycemia $=90 \pm 4 \mathrm{mg} / \mathrm{dl}^{-1}$ (Loizzo et al., 2010a); fasting plasma triglycerides $=$ $86 \pm 5 \mathrm{mg} / \mathrm{dl}^{-1}(n=12)$ (Loizzo et al., 2010c); fasting plasma insulin: $24 \pm 0.6$ $\mathrm{pMol} / /^{-1}$ (Loizzo et al., 2006); body weight $=42.5 \pm 0.5 \mathrm{~g}$ (Loizzo et al., 2010c); abdominal fat weight (epididymal fat pads $)=1.2 \pm 0.2 \mathrm{~g}$ (Loizzo et al., 2010a); nonfasting plasma corticosterone $=23 \pm$ $4 \mathrm{ng} / \mathrm{ml}^{-1}$ (Loizzo et al., 2010a); and plasma leptin $=4.5 \pm 0.4 \mathrm{ng} / \mathrm{ml}^{-1}$ (Loizzo et al., 2006). Locomotor activity was recorded by radar devices in six control and six stressed mice for seven consecutive days (Migliore, 2007). $* P<$ $0.05 ; * * P<0.01 ; * * *<0.001$. 
A

\section{Hypothalamus}

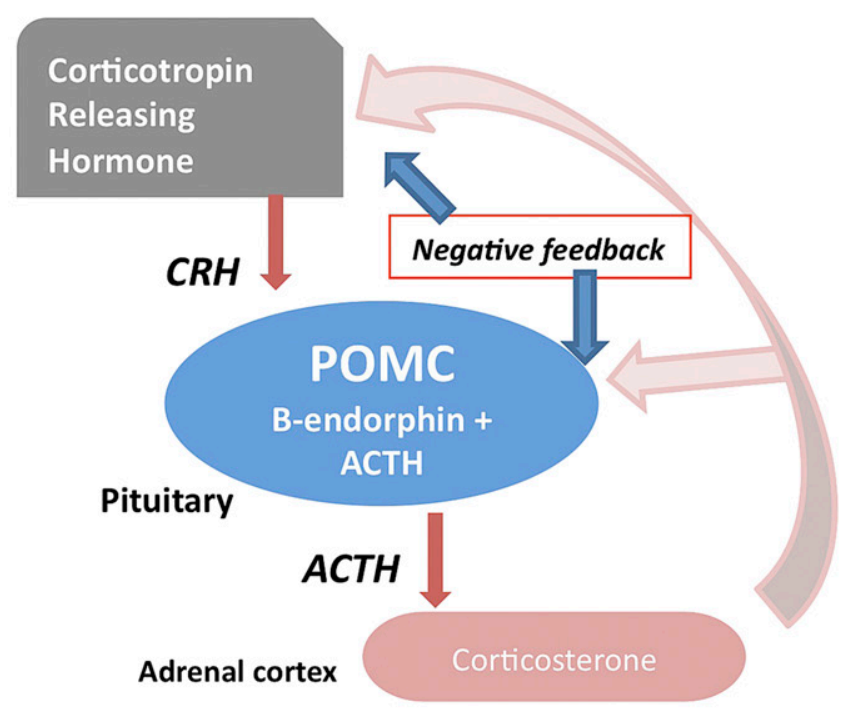

B

\section{Hypothalamus}

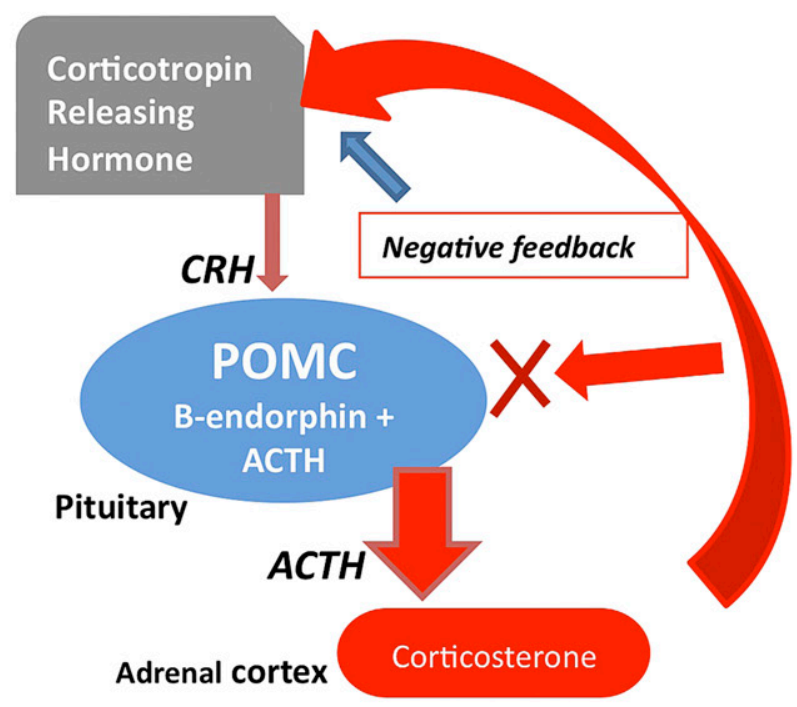

C

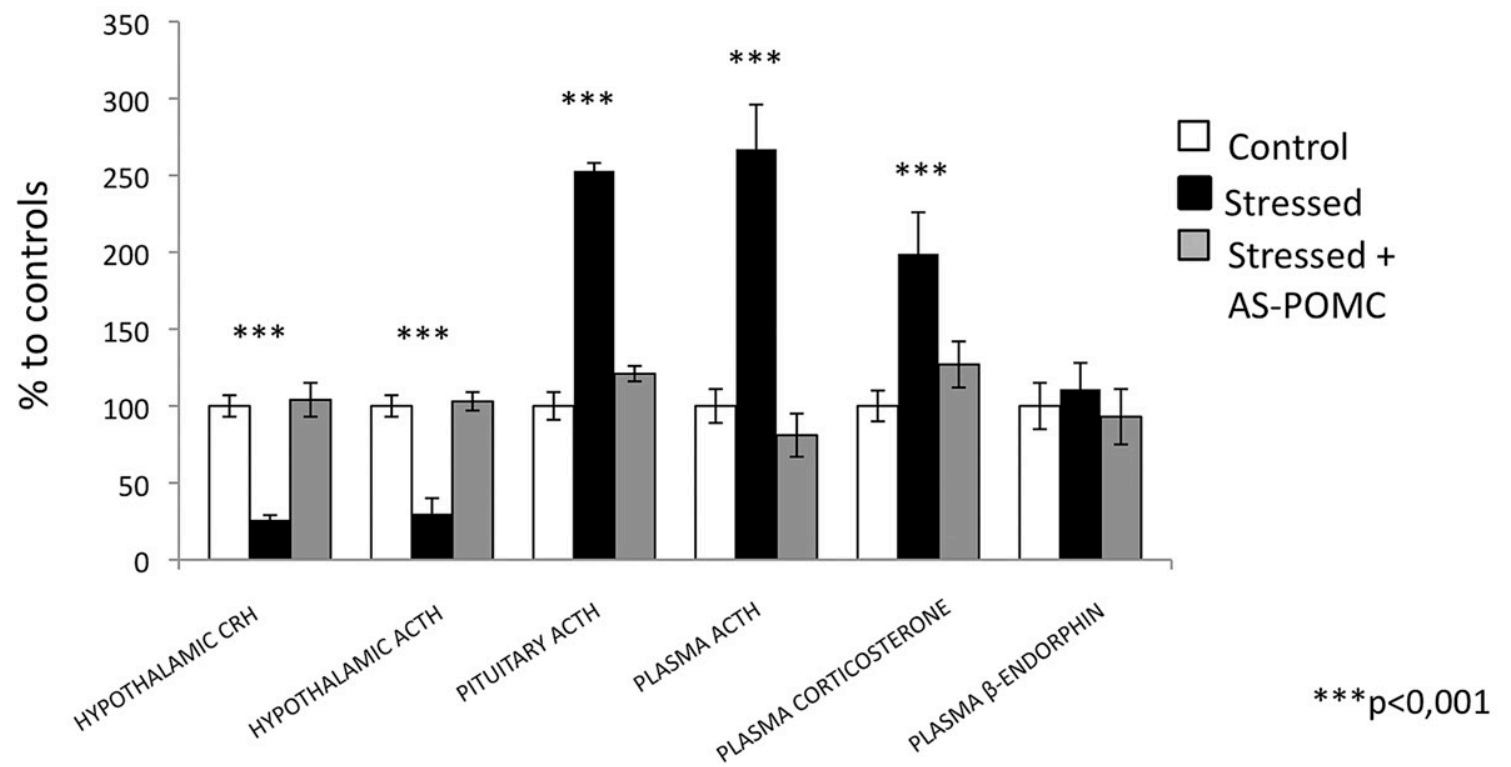

Fig. 2. (A) Proposed pathogenesis of the diabetes model according to the normal-physiologic feedback mechanism following single stress hormone level increases but returning to normal values within minutes or hours due to the hypothalamic and pituitary feedback regulatory mechanisms (see the arrows). (B) However, during the stress period an important pathophysiologic mechanism ensues: day by day, apparently cumulative adversity increases the stress sensitivity and risk of adverse health outcomes. Therefore, repeated stress results in breakdown of pituitary feedback negative control mechanisms in developing mice, finally resulting in long-lasting, exaggerated synthesis/release of ACTH and corticosterone in adults (red arrows). Hormone levels during this period are shown in (C). (C) The graph shows hormone levels in stressed mice at 90 PND (black columns), as percentage of control values (white columns). In this case, please note that CRH and ACTH levels in the hypothalamus are strongly decreased vs. controls (due to effective hypothalamic feedback control mechanisms), whereas pituitary and plasmatic ACTH, and plasmatic corticosterone are strong and endure increases at least for 70 days after the end of stress, presumably due to failure of pituitary feedback control hormone mechanisms). All of these effects are prevented in animals stressed and treated with AS-POMC (shaded columns), while treatment with naloxone produces minor or no changes [not reported here, published in Loizzo et al. (2010a)]. Control values: hypothalamic CRH $=21.3 \pm 1.5 \mathrm{pg} / \mathrm{ug}^{-1} \mathrm{proteins}$; hypothalamic ACTH $=10.7 \pm 0.7 \mathrm{pg} / \mu \mathrm{g}^{-1}$ proteins; pituitary ACTH $=1816 \pm 160 \mathrm{pg} / \mathrm{gg}^{-1}$ proteins; plasma ACTH $=75 \pm 5.2 \mathrm{pg} / \mathrm{ml}^{-1}$; and plasma corticosterone $=23.7 \pm 1.6 \mathrm{ng} / \mathrm{ml}{ }^{-1}$. Plasma $\beta$-endorphin was strongly enhanced on PND 21, but did not show consistent alterations during adult ages. All of the data in (C) were adapted from data originally published in Galietta et al. (2006). Consistent and enduring changes of endogenous brain opioid activity were also evidenced in adult mice following postnatal stress (see sections Prenatal and Neonatal Procedures of the Model and Early Stress and the Endogenous Opioid System in this paper). $* P<0.05 ; * * P<0.01 ; * * * P<0.001$. Please note that euthanasia was performed in nonfasting animals: in this case, the three mice in each cage were picked up and underwent rapid euthanasia at the same moment by three different investigators to avoid excess stress.

working correctly, whereas pituitary mechanisms deputed to the control of synthesis/release of ACTH and other POMC-derived peptides in corticotropic cells failed to be modulated by enhanced corticosterone and ACTH plasma levels. Therefore, we found enduring abnormally high ACTH and corticosterone levels in the pituitary/plasma of adult-aged 
stressed animals (Galietta et al., 2006; Loizzo et al., 2010a). (Fig. 2, A-C).

This appeared to be the keystone principle for understanding our diabetes model: repeated stress procedures apparently produced breakdown of pituitary-adrenal negative feedback control mechanisms. This, in turn, resulted in strong and enduring enhancement of plasma ACTH, and therefore of plasma corticosterone levels. These data enforced the hypothesis that both endogenous ACTH-corticosterone and opioidsystem hyperfunction induced by our stressful procedures (see Early Stress and the Endogenous Opioid System) were responsible for determining the appearance of diabetes-like alterations in adult male mice. The aforementioned hypothesis was also further confirmed through an inverse approach (see Some Stress-Induced Alterations Were Prevented by Administration of an Opioid Receptor Antagonist Drug and Some StressInduced Alterations Are Still of Undetermined Origin).

\section{Understanding Pathogenesis of Specific Diabetes-Like Alterations through Specific Pharmacological Treatment}

Some Stress-Induced Alterations Were Prevented by Administration of an Opioid Receptor Antagonist Drug. Alteration of several parameters described in adult mice, following postnatal double stressful procedures (presumably, also travel stress of pregnant mother may have induced a certain sensitization of HPA in mice fetuses; see Hiroi et al., 2016), were prevented by administering to our mice the opioid receptor-antagonist naloxone during the nursing period. Therefore, these alterations can be defined as prevalently opioid sensitive, and include metabolic parameters such as increase of body weight and abdominal fat weight (d'Amore et al, 1996; Loizzo et al, 2010a); increase of food caloric efficiency (Loizzo et al, 2012a); and increase of some brain mitochondrial parameter efficiencies including reduced latency of $\mathrm{NAD}(\mathrm{P}) \mathrm{H}$ fluorescence imaging evoked to cortical pathway inputs in ex vivo brain slices (Loizzo et al, 2012b), alteration of immunological parameters (increase of some cytokines of the Th-1-type released by splenocytes, decrease of some cytokines of the Th-2-type, increase of natural killer cell activity, increase of splenocyte proliferative activity (Loizzo et al, 2002), alteration of behavioral parameters (increased efficiency of passive avoidance test; see Loizzo et al, 2012a), and alteration of neurophysiologic parameters (reduced latency of visual evoked responses and oscillatory responses; see Loizzo et al, 2012b, and others) (see also Figs. 3-5; Supplemental Material).

Several Stress-Induced Alterations Were Prevented by Modulating Endogenous Proopiomelanocortin Activity. We observed that both endogenous opioid- and ACTHcorticosterone system activities are linked at the anterior pituitary level to promote the synthesis/release of the pro-hormone POMC. Therefore, in one of our laboratories (Spampinato et al., 1994) antisense oligodeoxinucleotides (ASs) were designed to bind to a selected target mRNA sequence by Watson-Crick base pairing, leading to the formation of a double-stranded sequence, which resulted in blockade of mRNA processing or translation. A patent for AS-POMC, and its variants for the prevention and treatment of post-traumatic stress disorder, owned by Istituto Superiore di Santià (ISS), Roma is held at the Ufficio Italiano
Brevetti e Marchi (Patent No. 102007901481765). No patents were asked for use of prevention or treatment of diabetes. Thus, we found that following administration (during the nursing period) of an antisense oligodeoxinucleotide complementary to a region of $\beta$-endorphin mRNA (AS-POMC), a dose-related reduction of synthesis of POMC-derived peptide ACTH and $\beta$-endorphin was produced in adult male mice (Spampinato et al., 1994; Loizzo et al., 2003; Galietta et al., 2006). Therefore, a series of experiments was performed to identify those diabeteslike parameters induced by the stress model that were not (or only in part) prevented by naloxone treatment in stressed mice, but were efficaciously and dose-dependently prevented in adult mice by daily treatment with AS-POMC administered during the nursing period. These parameters were identified as prevalently ACTH-corticosterone sensitive, and included metabolic parameters (enhanced fasting glycemia; see Loizzo et al., 2010a); some brain mitochondrial parameter efficiencies, such as increased amplitude of $\mathrm{NAD}(\mathrm{P}) \mathrm{H}$ fluorescence imaging evoked to cortical pathway inputs in ex vivo brain slices (Loizzo et al., 2012b); neuroendocrine parameters, such as reduced $\mathrm{CRH}$ and $\mathrm{ACTH}$ at hypothalamic level, enhanced ACTH at pituitary and plasmatic levels, and enhanced corticosterone at plasmatic levels (Galietta et al., 2006; Loizzo et al., 2010a); and some vascular parameters, such as reduced contracting response to noradrenaline in isolated ex vivo aorta rings and enhanced relaxing response to acetylcholine (Loizzo et al., 2015). There was also a certain amount of interference exerted by naloxone on some endocrine parameters. For example, AS-POMC treatment drew the abnormally enduring increase of ACTH levels to normal levels produced by stress in the pituitary and plasma, but naloxone treatment in part also reduced the abnormal increase (Loizzo et al., 2010a). Of course, all opioid-sensitive alterations produced by the stress model were also dose-dependently prevented by the administration of AS-POMC during the nursing period (Loizzo et al., 2010a, 2012a,b) (Figs. 4 and 5; see also Supplemental Material).

Some alterations that belonged to the same pathophysiologic type were in general prevented by the same treatment. For example, several alterations induced by stress on the immune system were prevented by naloxone (Fig. 3) (Loizzo et al., 2002). Some metabolic alterations (alteration of body weight, abdominal weight, and fat pad weight) also were prevented by naloxone, whereas hyperglycemia was not prevented by naloxone but was consistently prevented by AS-POMC (Fig. 4C) (Loizzo et al., 2010a). Antiociceptive effects induced by stress on prepuberal/puberal mice (up to about 45 PND), and enhanced performance of visual evoked potentials in adults were prevented by naloxone and also by AS-POMC (Loizzo et al., 2012b), whereas decreased sensitivity of ex vivo aorta isolated rings to noradrenaline contracting effects in stressed mice was prevented by AS-POMC but not by naloxone (Loizzo et al., 2015).

Some Stress-Induced Alterations Are Still of Undetermined Origin. Besides the previously described parameters, another series of parameters was modified in adult mice following postnatal stress; however, prior to this current study we could not demonstrate with reasonable certainty the mechanisms through which these alterations were produced. This is in reference to some metabolic alterations, such as an increase in plasma insulin, leptin, and triglycerides (Loizzo et al., 2006); some behavioral alterations, such as reduced immobility time in the Porsolt test (Franconi et al., 2004); some neurophysiologic alterations, such as enhanced long-term 
A

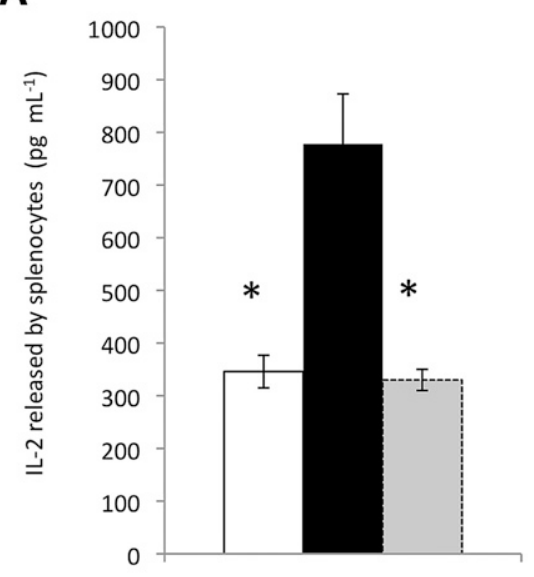

C

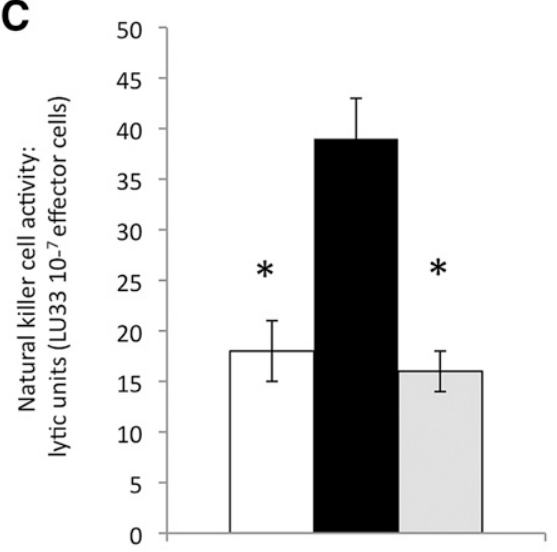

B

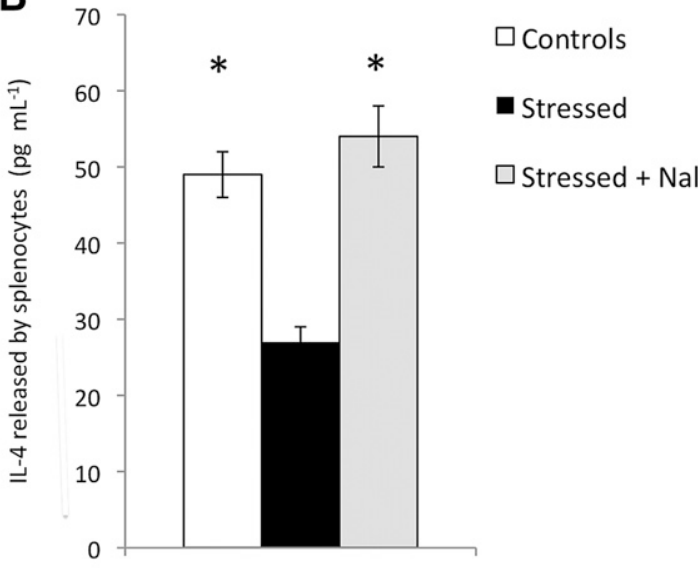

D

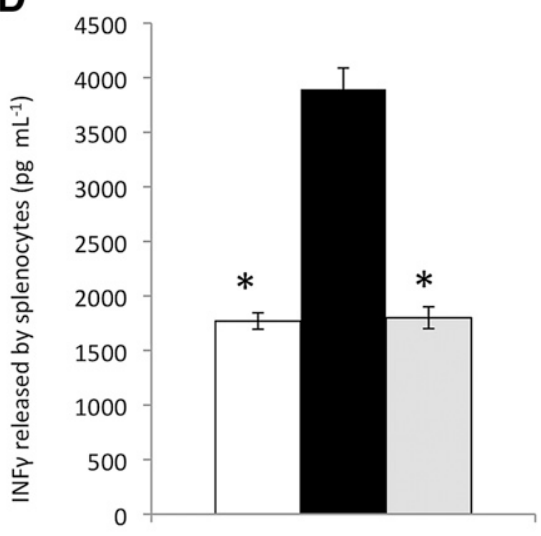

Fig. 3. Immunologic alterations induced by stress. The stress model induced: 1) long-term increased release of some Th-1-type cytokines [such as interleukin (IL)-2, interferon- $\gamma$, and tumor necrosis factor- $\alpha$ ] produced by splenocytes ex vivo, stimulated with phytohemoagglutinin); 2) reduced release of some Th-2-type cytokines (such as IL-4 and IL-10); 3) enhanced natural killer-cell activity; and 4) enhanced splenocytes proliferative activity. Data reported here are related to cytokine IL-2 (A), cytokine IL-4 (B), interferon- $\gamma$ (D), and natural killer-cell activity (C). Data were gathered at 110 PND in control mice (open columns), stressed mice (black columns), and mice stressed and daily treated with $(-)$ naloxone $\mathrm{HCl}$, $1 \mathrm{mg} / \mathrm{kg}^{-1}$, as weight of the base (light gray columns), during the nursing period (2-21 PND). A further control group was obtained through treatment of stressed mice with the (+)naloxone enantiomorph, which was devoid of antagonistic effects (data not reported here), and its effects were quite similar to those obtained in mice stressed and treated with saline. The asterisk indicates consistent differences vs. stressed animals (at least $P<0.05$ ), five animals per group. All data were adapted from data originally published in Loizzo et al. (2002).

\footnotetext{
*P at

least $<0,05$
}

potentiation in the hippocampus (Franconi et al., 2004), enhanced electroencephalogram total power, and enhanced power of very fast frequency bands in electroencephalograms $(90-400 \mathrm{~Hz})$ recorded during active wakefulness (Loizzo et al., $2012 \mathrm{~b}$ ); and some gene findings alterations, such as enhanced brain mRNA expression of $11 \beta$-hydroxysteroid dehydrogenase type 1 (HSD11B1), reduced brain mRNA expression of $11 \beta$ hydroxysteroid dehydrogenase type 2 (HSD11B2) (Loizzo et al., 2010c), and others. Some effects listed here are depicted in Fig. 6 (see also Supplemental Material).

\section{The Enduring Acute Stress Hypothesis}

Our stress model produces increased activity in the ACTHadrenal axis and endogenous opioid systems, and these activities are accompanied not only by diabetes-like dysmetabolic parameters but also by increased efficiency of some neurophysiologic-neurometabolic parameters (Loizzo et al., 2012b; see also Some Stress-Induced Alterations Are Still of Undetermined Origin and Supplemental Material). We suggest that these findings, which according to previously described results are triggered by failure of pituitary feedback control mechanisms, depend on a pathogenesis that involves a unique pathophysiological phenomenon, i.e., an abnormally enduring alarm stress reaction. Our stress model is accompanied by a constellation of physiologic-metabolic alterations extraordinarily similar to those induced by acute stress reactions (see Loizzo et al., 2012b), as described in earlier investigations (Selye, 1976), but with at least one main difference: alterations that occur after an acute stress (or following glucocorticoid administration) are observed for minutes or hours, whereas following our stressful procedures the alterations of said parameters and neurophysiologic performance lasts for several months, and may last lifelong (Loizzo et al., 2006, 2012a,b). Importantly, increased brain performance requires increased energy availability. Therefore, during the adulthood period in our mice compensatory homeostatic mechanisms, including increased efficiency of energy production, are mobilized through enhanced fuel availability, which in our hypothesis is supplied by plasma hyperglycemia and hyperlipidemia. These events require enhanced mitochondrial activity, thus responding to increased energy demand by increased performance of brain and other organs (Loizzo et al.,2010b, 2012b). Mitochondrial energy 
A

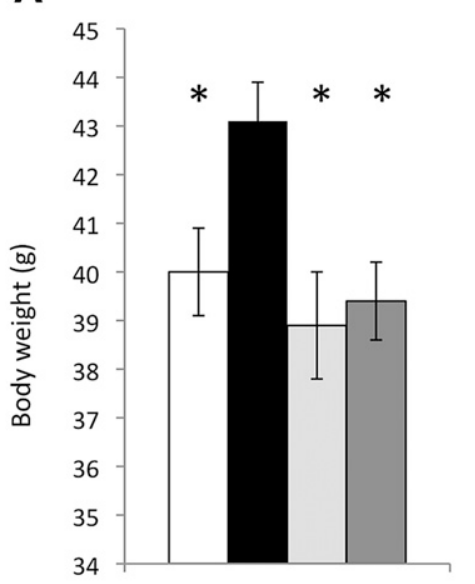

B

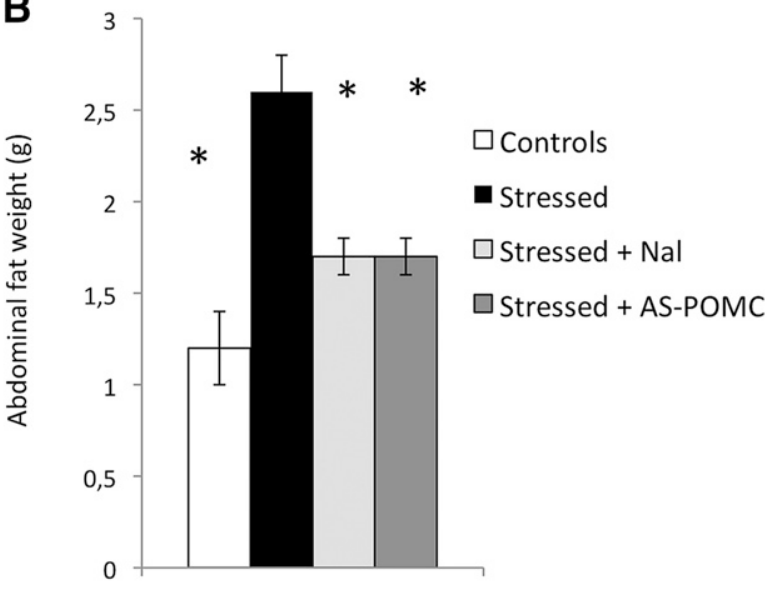

D$$
\text { C }
$$

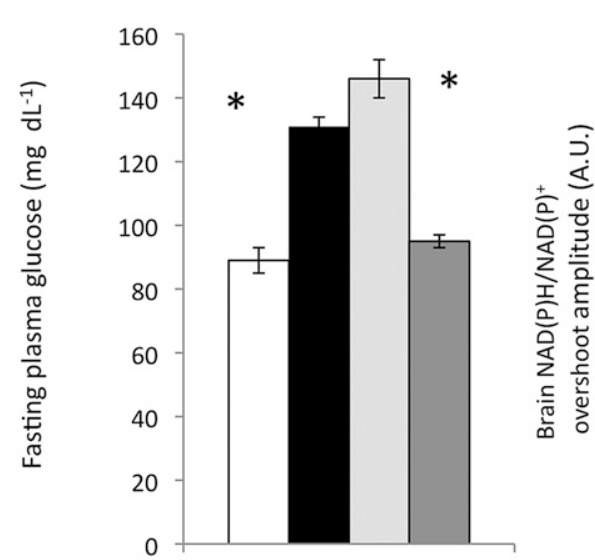

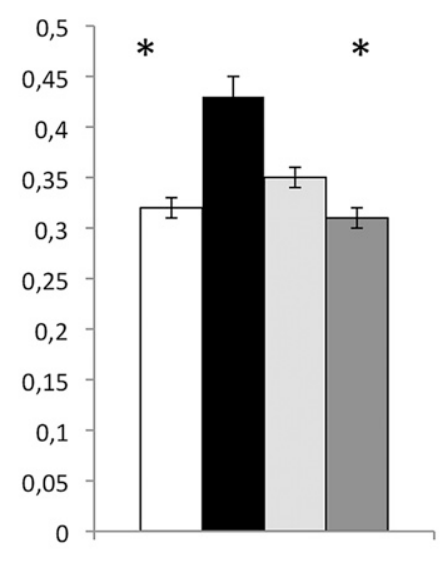

Fig. 4. Metabolic alterations induced by stress. The stress model induced consistent alterations of several metabolic parameters. Alterations of some parameters [e.g., body weight increment curve (A) and increased weight of epididymal fat pads (B)] were prevented by both naloxone and AS-POMC, whereas other alterations [e.g., increased glycemia (C) and increased $\mathrm{NAD}(\mathrm{P}) \mathrm{H}$ overshoot amplitude, a parameter indicative of mitochondrial activity (D)] were not prevented by naloxone (light gray columns), but were consistently prevented by AS-POMC (shaded columns). The asterisk indicates consistent difference vs. stressed animals (at least $P<0.05$ ). Data depicted in (A) (C) were taken from Loizzo et al. (2010a); data in (D) were published in Loizzo et al. (2012b).

$$
\begin{gathered}
* \mathrm{P} \text { at } \\
\text { least }<0,05
\end{gathered}
$$

reactions quite similar to those detected in our diabetes model, as measured by $\mathrm{NAD}(\mathrm{P}) \mathrm{H}$ autofluorescence signal, have also been observed in other diabetes models, as well as in other animal models of chronic diseases, thus representing unspecific early markers of neurodegeneration (Moreira et al., 2003; Loizzo et al., 2010b; Newsholme et al., 2012). Therefore, these reactions may prelude to cell damage and disease complications. We speculate that the previously described findings and the enduring acute stress reactions put mice in a favorable survival situation versus controls. However, following long periods of enhanced efficiency of the previously described metabolic systems, an evolution of the model may start, i.e., following overexploitation of energy-producing mechanisms these structures may become exhausted, leading the organism to a frank pathologic condition, and may progress to diabetes complications.

Our studies also point to a link between the central nervous system, especially the hypothalamus, and peripheral mechanisms associated with obesity that may lead to type- 2 diabetes. Malfunction of central nervous system networks that control energy intake and expenditure is a major mechanism for the development of obesity that contributes to pathologic changes in peripheral organs and tissues, including insulin resistance, driven by proinflammatory responses involving immune cells and adipocytes (Begg and Woods, 2013). Hypothalamic inflammation is characterized by glial reactivity, secretion of cytokines, and increased levels of intracellular inflammatory signals. In rodent models of long-term diet-induced obesity, glial activation is sustained and the vasculature undergoes angiogenesis. In addition, hypothalamic POMC neurons, which inhibit food intake and stimulate energy expenditure, are reduced (Thaler et al., 2012).

Although we did not investigate any alteration of hypothalamic glial reactivity in our stress model, we note that Gerber and Bale (2012) adopted, as a model of chronic stress, mice deficient in corticotropin-releasing factor receptor-2, and observed involvement of hypothalamic astrocytes in the 
A
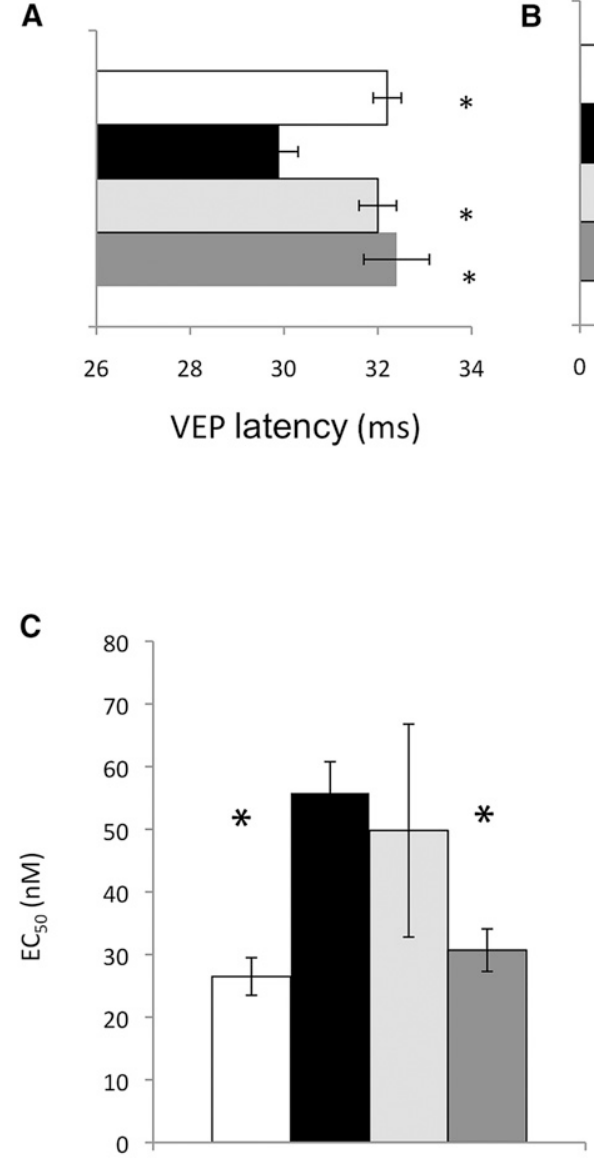

Aorta response to $\mathrm{Nad}$

B

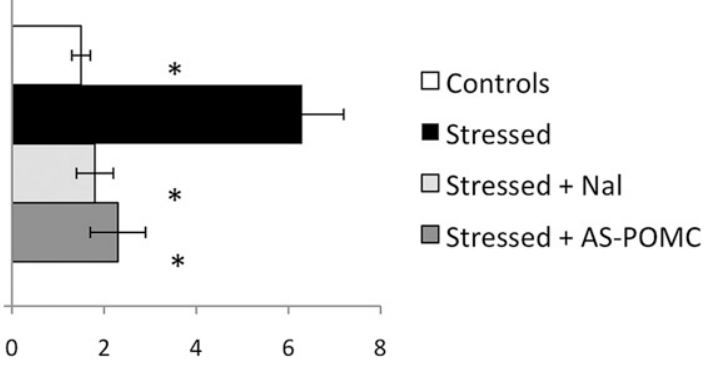

Tail flick test (s)

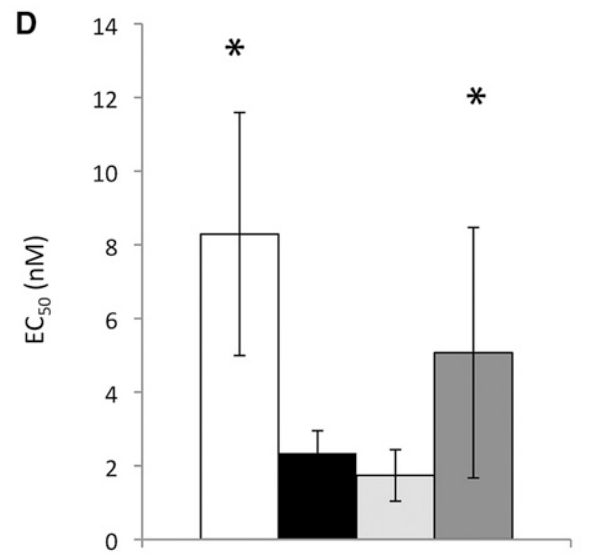

Aorta response to $\mathrm{ACh}$
Fig. 5. Physiologic and neurobehavioral alterations induced by stress. Alteration of some parameters induced by the stress model on animals (e.g., faster visual evoked potentials and delayed nociceptive responses) were prevented by both naloxone and AS-POMC, whereas other alterations (e.g., decreased contracting responses to noradrenaline in ex vivo isolated aorta rings and enhanced relaxing responses to acetylcholine) were not prevented by naloxone, but were prevented by AS-POMC (borderline significant in the latter case). VEP denotes visual evoked potentials (in milliseconds), Nad denotes noradrenaline, and $\mathrm{ACh}$ denotes acetylcholine. Data in (A) and $(\mathrm{B})$ were published in Loizzo et al. (2012b); data in (C) and (D) were published in Loizzo et al. (2015).

$$
\begin{gathered}
* P \text { at } \\
\text { least }<0,05
\end{gathered}
$$

exacerbation of stress pathway dysregulation. Further studies are necessary to better explore this relationship between chronic stress and hypothalamic inflammatory reactions.

\section{Comments on Model Implications}

The Stress Model and Female Sex. Clinical and laboratory studies agree that women and men have different disease risks, since women of reproductive age are protected from metabolic and cardiovascular disease compared with postmenopausal women and men. In rats, several responses to stress and consequences of early maternal separation are gender dependent: male and female rats appear to have different behavioral profiles and coping strategies in many behavioral experiments (Vetulani, 2013). It is, therefore, possible that the history of early adversities is expressed by different hormonal balance and metabolic equilibrium results in the two sexes. In fact, we applied our stress model also to female mice, and performed some investigations in our laboratories (Loizzo et al., 2010c). Different metabolic patterns were found between sexes (see Table 2). From these investigations we gathered some information, as detailed subsequently.
The first interesting information is given by the evolution of body weight. At weaning, following 20 days of stress (from 2 to 21 PND), body weight in stressed males is consistently lower versus their controls; however, afterward stressed male mice rapidly gain weight and at 90 PND they become heavier than controls (Table 2). We underline that disturbed growth during important periods of early development, followed by rapid weight gain, is associated with increased risk of type-2 diabetes in humans (van Abeelen et al., 2012), and we speculate that this mechanism may be suggested as one pathogenetic determinant for diabetes-like syndrome in our mice as well. Conversely, our stressed female mice did not show different body weights versus controls, neither at weaning nor in the following days up to 90 PND (Loizzo et al., 2010c). Moreover, stressed females did not show consistent alterations differently from males of nociceptive sensitivity (at 30 PND) of fasting glycemia, nonfasting corticosterone levels, and HSD11B1 and HSD11B2 mRNA mean expression in the brain cortex versus control females at 90 PND (see Loizzo et al., 2010c) (Table 2).

These results suggest that etiopathogenetic mechanisms of metabolic alterations, previously hypothesized in male mice, need to be evaluated differently when females are considered. 
A

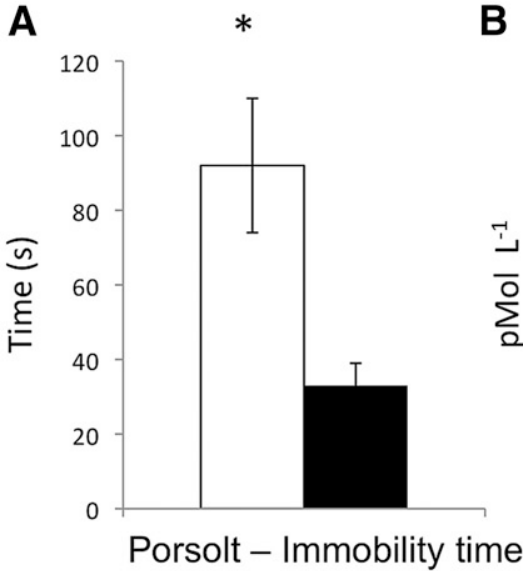

B

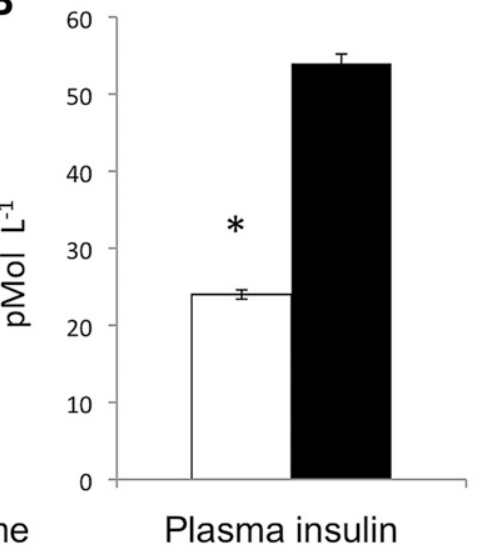

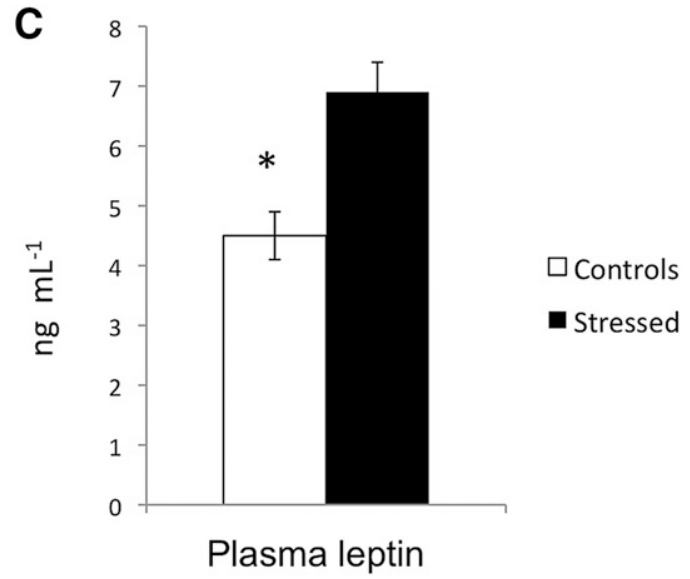

D

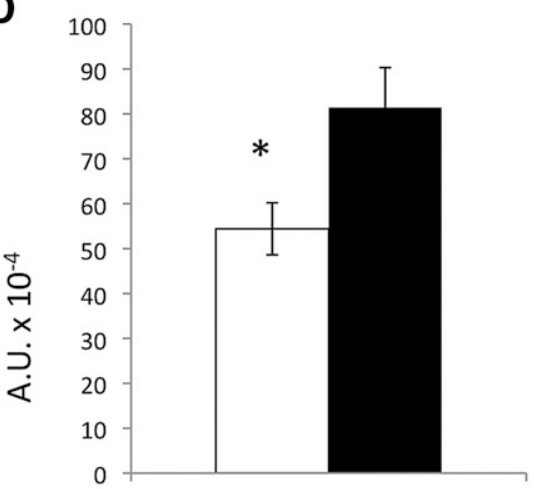

HSD11-B1 gene expression

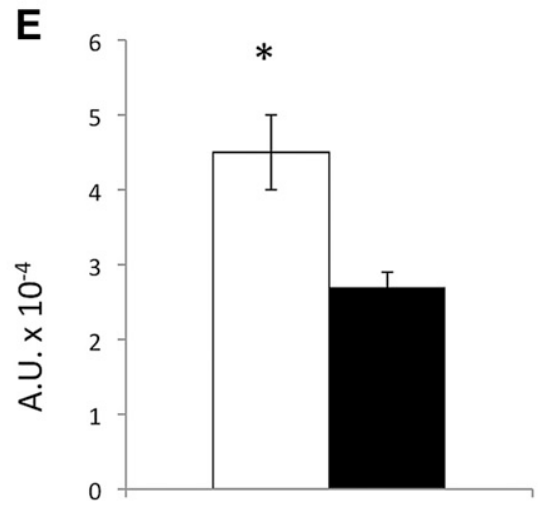

HSD11-B2 gene expression

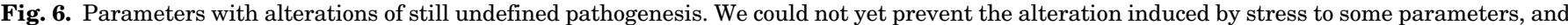

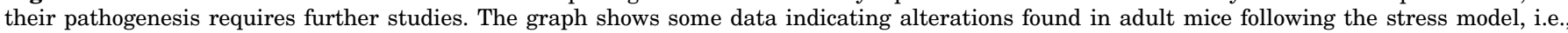

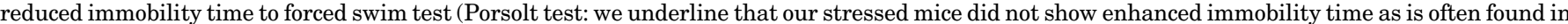

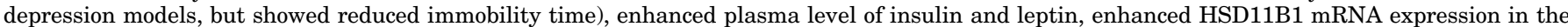

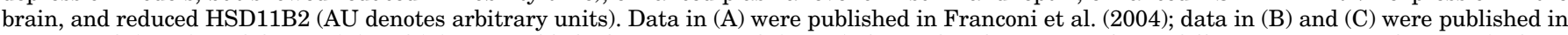

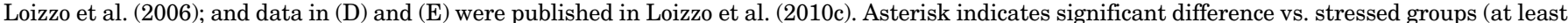
$P<0.05)$.

In particular, we underline that the pattern of HSD11B1 mRNA mean expression in the brain cortex was consistently enhanced in stressed male mice. HSD11B1 reduces 11-dehydrocorticosterone to corticosterone, which activates glucocorticoid receptors, thus suggesting that this mechanism may further increase physiopharmacological activity exerted by the hyperactivity of the endogenous glucocorticoid corticosterone found in our stressed male mice, and presumably produces further metabolic damage. Conversely, the HSD11B2 pattern (which converts corticosterone to the inactive 11-dehydrocorticosterone) was consistently decreased after the stress model in males, thus further enforcing the

TABLE 2

Pattern of physiologic and metabolic parameters in male and female mice following our stress model

The number of experimental mice for body weight was at least 60 mice per group. Hot plate was assessed at 30 PND, with at least 25 mice per group. For glycemia the number was at least 20 mice per group; for plasma corticosterone it was at least eight per group; and for basal HSD11B1, HSD11B2, and mRNA mean expression in the brain cortex it was six mice per group. Stressful procedures were not, or minimally, effective in females. All data expressed here were adapted from data originally published in Loizzo et al. (2010c). Values are expressed as mean \pm S.E.M. AU is for arbitrary units. $* P<0.05$ denotes consistent difference vs. control females; \#P<0.05 denotes consistent difference vs. controls of the same sex.

\begin{tabular}{|c|c|c|c|c|c|c|c|}
\hline \multirow[b]{3}{*}{ Sex and Treatment } & \multicolumn{2}{|c|}{ Body Weight } & \multirow[b]{2}{*}{ Hot Plate (30 PND) } & \multirow[b]{2}{*}{ Glycemia (90 PND) } & \multirow[b]{2}{*}{ Corticost (90 PND) } & \multirow[b]{2}{*}{ HSD11B1 (90 PND) } & \multirow[b]{2}{*}{ HSD11B2 (90 PND) } \\
\hline & $21 \mathrm{PND}$ & 90 PND & & & & & \\
\hline & $g$ & $g$ & $s$ & $m g / d l^{-1}$ & $\mu g / d l^{-1}$ & $A U\left(10^{-4}\right)$ & $A U\left(10^{-4}\right)$ \\
\hline Control males & $15.7 * \pm 0.1$ & $42.5^{*} \pm 0.5$ & $39.2^{*} \pm 1.8$ & $93.0 \pm 4.6$ & $2.0 \pm 0.22$ & $54.4^{*} \pm 5.8$ & $4.5^{*} \pm 0.54$ \\
\hline Stressed males & $14.9 \# \pm 0.1$ & $44.8 \# \pm 0.5$ & $50.1 \# \pm 1.6$ & $130.4 \# \pm 3.7$ & $3.8 \# \pm 0.61$ & $81.4 \# \pm 8.9$ & $2.7 \# \pm 0.16$ \\
\hline Control females & $14.8 \pm 0.1$ & $33.3 \pm 0.5$ & $35.0 \pm 1.1$ & $91.9 \pm 3.2$ & $2.1 \pm 0.6$ & $41.7 \pm 4.3$ & $3.1 \pm 0.48$ \\
\hline Stressed females & $14.5 \pm 0.2$ & $34.5 \pm 0.6$ & $38.4 \pm 2.3$ & $88.2 \pm 3.6$ & $1.9 \pm 0.3$ & $45.1 \pm 7.0$ & $3.8 \pm 0.72$ \\
\hline
\end{tabular}

AU, arbitrary units. 
same physiopharmacological mechanisms as HSD11B1 does. Moreover, the plasma levels of corticosterone and ACTH and brain HSD11B1 and HSD11B2 mRNA expression are not significantly modified in stressed females versus their controls (Loizzo et al., 2010c) (see Table 2). Thus, the present findings strongly confirm and extend the hypothesis that the absence of alteration in the HPA hormone pattern induced by stress in females, and also the absence of alteration in the mRNA expression of HSD11B1 and HSD11B2 in females, could suggest some explanations for the differences in metabolic and hormonal long-term alterations found in stressed males versus stressed females in mice.

The Stress Model and Overfeeding Models. Several animal models of obesity described in the literature are somehow heterogeneous, since they exploit spontaneous mutations or diet-induced obesity in rodents; however, these latter models are often used to study polygenic causes of obesity and are believed by several investigators to better mimic the state of common obesity in humans, and may be the best choice for testing prospective therapeutics. These animal models may also show some of the most frequent comorbidities of obesity, such as hyperglycemia, insulin resistance, or diabetes-like syndromes (Lutz and Wood, 2012; Reyes, 2012; Habbout et al., 2013; Griffin et al., 2016; Heydemann, 2016); similar metabolic and immunologic alterations are observed in our model as well (Supplemental Material; Table 3). In synthesis, the three conditions (human type-2 diabetes, mouse high-fat diet/overfeeding syndrome, and our stress model of type-2 diabetes) share a number of similar alterations, as shown in Table 3, and we speculate that all three syndromes may also share some of the neuroendocrine pathogenetic mechanisms described in the present paper (Table 3).

\section{Future Developments and Self-Criticism}

Stress-induced failure of pituitary negative feedback mechanisms that control POMC-derived ACTH-corticosterone and endogenous opioid hyperactivity appears to be of crucial importance in the pathogenesis of the previously described diabetes-like syndrome. However, some important questions still need to be answered, and the mechanisms need to be confirmed and defined.

Studies on Deep Pathogenetic Mechanisms. Molecular and gene mechanisms that are involved in the failure of negative feedback mechanisms in the pituitary still need to be understood. What exactly is the damage induced by stress?
Our data (Galietta et al., 2006; Loizzo et al., 2010a) showed that our model produced failure of negative feedback hormone regulation in the pituitary. However, of course, we need to know what the failure of negative pituitary feedback mechanisms really means, and where and how, exactly, are these mechanisms produced.

Studies on Etiologic Determinants. The etiology of the model also requires further investigation. The protocol we followed over several years gave results that were repeated in our laboratories with a high rate of reproducibility and reliability. However, in our previous papers we may have not underlined with enough emphasis the possible influence exerted by prenatal travel stress on the postnatal period (see also Loizzo et al., 2002). We reported that CD1 pregnant mice arrived at our laboratory on the 14th day of conceptional age, following a travel period from the factory. It is well known that repeated, although soft vibrations (and travel-producing vibrations) applied to the whole body produce an increase in circulating ACTH and cortisol/corticosterone in humans and laboratory animals (Perremans et al., 2001; Cardinale et al., 2010). Stress applied during pregnancy sensitizes the HPA axis, increasing stress-induced corticosterone secretion in preweanling rats and prolonging stress-induced corticosterone secretion in the adult (Peters, 1982; Fride et al., 1986; Takahashi et al., 1988; Henry et al., 1994; Maccari et al., 1995). Therefore, whether prenatal, enhanced endogenous corticosteroid exposure to the fetus environment could have rendered our pups more susceptible to pathologic outcomes when further stresses were administered in the postnatal period should be investigated. This may have happened also in the absence of apparent changes in the behavior and hormonal levels in steady-state/control conditions in newborns, and in fact we always described alterations found in our postnatal stressed mice versus baseline data of postnatal control mice. Therefore, we may hypothesize that these latter animals' physiologic and psychologic parameters can be challenged only when further postnatal stress is also administered. Other investigators have recently demonstrated that stress of the two-hit type may produce effects similar to those we found: according to Vargas et al. (2016), early life stress increases metabolic risk and HPA axis reactivity when it is combined with postweaning social isolation in rats (see also Hackett and Steptoe, 2017).

A Bridge to Developmental Roots of Some Chronic Diseases of Adults? Much work has been dedicated to studies of the developmental bases of adult diseases. The

TABLE 3

Similarities among human type-2 diabetes, high fat diet/overfeeding model, and the present model From data published in Reyes (2012), Habbout et al. (2013), Griffin et al. (2016), Heydemann (2016), and by the authors (single references for our groups are reported in the tables and figures $3,4,5$, and 6 ).

\begin{tabular}{ll}
\hline Number & \multicolumn{1}{c}{ Similarities among Models } \\
\hline 1 & Body weight gain \\
2 & Adipocytes hypertrophy \\
3 & Hyperglycemia \\
4 & Hyperinsulinemia \\
5 & Hypercorticosteronemia/hypercortisolemia \\
6 & Increased fasting leptin levels \\
7 & Inflammation with increases in inflammatory cytokines \\
8 & Sexually dimorphic response to the model \\
9 & Hypothalamus-pituitary-adrenal axis-hyperactivity/dysregulation \\
10 & Vascular alterations \\
\hline
\end{tabular}


animal models described in the literature indicate that preand postnatal stress may be followed by increased risk for neurobehavioral, metabolic, cardiovascular, and renal diseases in adults (see Reagan, 2012; Jiang et al., 2013; Vargas et al., 2016). The present data suggest that the pathophysiologic basis of diabetes-like metabolic alterations in our model may reside in the failure of pituitary feedback control mechanisms, which is triggered by stress applied during the critical period of development of receptors and/or other cell organs. Therefore, we speculate that even subtle manipulation of stress parameters (types, timing, duration, intensity, repeatability, combination of pre- and postnatal stress, and presumably sex of subjects) may produce increased risk of these adult body and brain chronic diseases, which are presumed to have had their origin during developmental periods through involvement of different constellations of neuroendocrine/neurohumoral malfunctions.

Possible Therapeutic Applications. With the aforementioned perspective, therefore, possible therapies to treat type-2 diabetes should be considered when there is a reported history of prolonged stress conditions in the early age windows reported in our studies and described in this review. To achieve this goal, antagonists of the endogenous opioid receptors such as naloxone- and oligodeoxinucleotide-based therapies aimed at blocking expression of POMC-derived peptides could be hypothesized as prophylactic strategies.

\section{Conclusions}

We describe an early stress-derived mouse model that produces metabolic alterations similar to those found in human type-2 diabetes. In our opinion, the main novelties of our investigations consist in that we could correlate etiopathogenesis of these alterations to three sceneries:

a. A type-2 diabetes model in male mice, following the early complex stress model, is obtained when our complete protocol of experiments is applied. A synergistic pre- and postnatal stress mechanism can be suggested as a main cause in triggering the previously described effects (see also Maccari et al., 2014). Of course, other types of stress and different intensities/times of application may also induce analogous effects (see Vargas et al., 2016).

b. Following our stress model, two (partly) different series of diabetes-like alterations are produced in adult mice. One series depends mainly on hyperfunction of the endogenous opioid system, and its related alterations are prevented through the administration of naloxone during the nursing period. The other series depends mainly on hyperfunction of the ACTH-corticosterone system, and its related alterations are prevented through the administration of AS-POMC, which reduces both endogenous ACTH and endogenous opioid synthesis/hyperfunction at the brain and pituitary levels through POMC synthesis modulation. The enduring enhanced functions of the endogenous opioid system, together with ACTH-corticosterone system enhanced activity, are both necessary conditions for the triggering of diabetes-like alterations in our model.

c. We showed that hyperfunction of these two systems is accompanied by failure of feedback hormonal control mechanisms induced by our stress procedures at the pituitary level. This appears to be of great importance in the induced enduring hyperfunction of the two endogenous systems described herein and, therefore, in the induced triggering of diabetes-like syndrome.

Finally, as a finalistic speculation, our stress model produces findings that are compatible with an enduring acute stress reaction, which puts mice in favorable survival situations versus controls. However, prolonged hormonalmetabolic imbalances produced by stress are expected to also produce diabetes-like complications at later ages in stressed mice.

\section{Acknowledgments}

Paolo Renzi (University of Roma La Sapienza) inspired part of the logical structure and statistical elaboration of the data. We thank Andrea Fortuna and Sergio Palazzesi (ISS) for excellent technical assistance, Carla Campanella (ISS) for editing the manuscript, and Stefano Fidanza and Adriano Urcioli (ISS) for valuable animal care. We also thank Valter Tranquilli, Publishing Unit (ISS), for the iconographic job. In particular, we thank the generations of graduate students and young investigators who participated in this research with enthusiasm and fantasy. This paper is dedicated to Margherita Panchetti, with love, friendship, and gratitude.

S.L. is the guarantor of this work and, as such, had full access to all the data in the study and takes responsibility for the integrity of the data and the accuracy of the data analysis.

\section{Authorship Contributions}

Wrote or contributed to the writing of the manuscript: A. Loizzo, Spampinato, Campana, S. Loizzo.

\section{References}

Akil HA and Morano MI (1995) Stress, in Psychopharmacology: The Fourth Generation of Progress (Bloom FE and Kupfer DJ, eds) pp 773-785, Raven Press, Ltd., New York.

Barker DJP (1998) Mothers, Babies and Health in Later Life, 2nd ed, Churchill Livingstone, Edinburgh.

Barrès R and Zierath JR (2016) The role of diet and exercise in the transgenerational epigenetic landscape of T2DM. Nat Rev Endocrinol 12:441-451.

Begg DP and Woods SC (2013) The endocrinology of food intake. Nat Rev Endocrinol 9:584-597.

Birnbaum LS and Miller MF (2015) Prenatal programming and toxicity (PPTOX) introduction. Endocrinology 156:3405-3407.

Bouret S, Levin BE, and Ozanne SE (2015) Gene-environment interactions controlling energy and glucose homeostasis and the developmental origins of obesity. Physiol Rev 95:47-82.

Cardinale M, Soiza RL, Leiper JB, Gibson A, and Primrose WR (2010). Hormonal responses to a single session of wholebody vibration exercise in older individuals. Br J Sports Med 44:284-288.

Costa LG (1993) Muscarinic receptors and the developing nervous system, in Receptors in the Developing Nervous System, in Neurotransmitters (Zagon IS and McLaughlin PJ eds) vol 2, Chapman \& Hall, London.

d'Amore A, Mazzucchelli A, and Loizzo A (1995) Long-term changes induced by neonatal handling in the nociceptive threshold and body weight in mice. Physiol Behav 57:1195-1197.

d'Amore A, Mazzucchelli A, Renzi P, and Loizzo A (1996) Effect of naloxone on the long-term body weight gain induced by repeated postnatal stress in male mice. Behav Pharmacol 7:430-436.

De Ceballos ML and De Felipe C (1984) Circannual variation in opioid receptor sensitivity in mouse vas deferens. Eur J Pharmacol 106:227-228.

Denenberg VH and Karas GG (1959) Effects of differential infantile handling upon weight gain and mortality in the rat and mouse. Science 130:629-630.

Eriksson M, Räikkönen K, and Eriksson JG (2014) Early life stress and later health outcomes-findings from the Helsinki Birth Cohort Study. Am J Hum Biol 26: $111-116$

Ferrannini E (2014) Definition of intervention points in prediabetes. Lancet Diabetes Endocrinol 2:667-675.

Franconi F, Diana G, Fortuna A, Galietta G, Trombetta G, Valentini G, Seghieri G, and Loizzo A (2004) Taurine administration during lactation modifies hippocampal CA1 neurotransmission and behavioural programming in adult male mice. Brain Res Bull 63:491-497.

Fride E, Dan Y, Feldon J, Halevy G, and Weinstock M (1986) Effects of prenatal stress on vulnerability to stress in prepubertal and adult rats. Physiol Behav 37: $681-687$.

Galietta G, Loizzo A, Loizzo S, Trombetta G, Spampinato S, Campana G, Capasso A, Palermo M, Guarino I, and Franconi F (2006) Administration of antisense oligonucleotide against pro-opiomelanocortin prevents enduring hormonal alterations induced by neonatal handling in male mice. Eur J Pharmacol 550:180-185. 
Gerber AR and Bale TL (2012) Antiinflammatory treatment ameliorates HPA stress axis dysfunction in a mouse model of stress sensitivity. Endocrinology 153:4830-4837.

Griffin C, Lanzetta N, Eter L, and Singer K (2016) Sexually dimorphic myeloid inflammatory and metabolic responses to diet-induced obesity. Am J Physiol Regul Integr Comp Physiol 311:R211-R216.

Gustafsson L, Oreland S, Hoffmann P, and Nylander I (2008) The impact of postnatal environment on opioid peptides in young and adult male Wistar rats. Neuropeptides 42:177-191.

Habbout A, Li N, Rochette L, and Vergely C (2013) Postnatal overfeeding in rodents by litter size reduction induces major short- and long-term pathophysiological consequences. J Nutr 143:553-562.

Hackett RA and Steptoe A (2017) Type 2 diabetes mellitus and psychological stress-a modifiable risk factor. Nat Rev Endocrinol 13:547-560.

Hanson MA and Gluckman PD (2014) Early developmental conditioning of later health and disease: physiology or pathophysiology? Physiol Rev 94:1027-1076.

Henry C, Kabbaj M, Simon H, Le Moal M, and Maccari S (1994) Prenatal stress increases the hypothalamo-pituitary-adrenal axis response in young and adult rats. J Neuroendocrinol 6:341-345.

Heydemann A (2016) An overview of murine high fat diet as a model for type 2 diabetes mellitus. J Diabetes Res 2016:2902351.

Hiroi R, Carbone DL, Zuloaga DG, Bimonte-Nelson HA, and Handa RJ (2016) Sexdependent programming effects of prenatal glucocorticoid treatment on the developing serotonin system and stress-related behaviors in adulthood. Neuroscience 320:43-56.

Irazusta J, Tejedor-Real P, Varona A, Costela C, Gilbert-Rahola J, and Casis L (1999) Effect of neonatal handling on brain enkephalin-degrading peptidase activities. Neurochem Int 35:357-361.

Islam MS and Loots DT (2009) Experimental rodent models of type 2 diabetes: a review. Methods Find Exp Clin Pharmacol 31:249-261.

Jiang X, Ma H, Wang Y, and Liu Y (2013) Early life factors and type 2 diabetes mellitus. J Diabetes Res 2013:485082.

Kälin S, Heppner FL, Bechmann I, Prinz M, Tschöp MH, and Yi CX (2015) Hypothalamic innate immune reaction in obesity. Nat Rev Endocrinol 11:339-351.

Kiosterakis G, Stamatakis A, Diamantopoulou A, Fameli M, and Stylianopoulou F (2009) Long-term effects of neonatal handling on mu-opioid receptor levels in the brain of the offspring. Dev Psychobiol 51:439-449.

Kumari M, Head J, Bartley M, Stansfeld S, and Kivimaki M (2013) Maternal separation in childhood and diurnal cortisol patterns in mid-life: findings from the Whitehall II study. Psychol Med 43:633-643.

Levine S (1957) Infantile experience and resistance to physiological stress. Science 126:405.

Loizzo A, Campana G, Loizzo S, and Spampinato SM (2012a) Post-natal stress procedures induce long-term endocrine and metabolic alterations involving different pro-opiomelanocortin-derived peptides, in Neuropeptides in Neuroprotection and Neurodegeneration (Nyberg F, ed) pp 107-125, Taylor \& Francis Boca Raton, FL.

Loizzo A, Capasso A, Galietta G, Severini C, Campana G, and Spampinato S (2003) Vas deferens response to selective opioid receptor agonists in adult mice is impaired following postnatal repeated mild stress. Eur J Pharmacol 458:201-205.

Loizzo A, Loizzo S, Galietta G, Caiola S, Spampinato S, Campana G, Seghieri G, Ghirlanda G, and Franconi F (2006) Overweight and metabolic and hormonal parameter disruption are induced in adult male mice by manipulations during lactation period. Pediatr Res 59:111-115.

Loizzo A, Loizzo S, Lopez L, d'Amore A, Renzi P, Spampinato S, Di Carlo S, Bacosi A, Zuccaro P, and Pacifici R (2002) Naloxone prevents cell-mediated immune alterations in adult mice following repeated mild stress in the neonatal period. $\mathrm{Br} J$ Pharmacol 135:1219-1226.

Loizzo A, Spampinato SM, Campana G, Vella S, Fortuna A, Costa L, Capasso A Monteleone P, Renzi P, and Loizzo S (2012b) Enhanced brain performance in mice following postnatal stress. J Endocrinol 215:413-424.

Loizzo A, Spampinato SM, Fortuna A, Vella S, Fabi F, Del Basso P, Campana G, and Loizzo S (2015) Antisense versus proopiomelanocortin mRNA reduces vascular risk in a murine model of type-2 diabetes following stress exposure in early postnatal life. Peptides 64:34-39.

Loizzo S, Campana G, Vella S, Fortuna A, Galietta G, Guarino I, Costa L, Capasso A, Renzi P, Frajese GV, et al. (2010a) Post-natal stress-induced endocrine and metabolic alterations in mice at adulthood involve different pro-opiomelanocortinderived peptides. Peptides 31:2123-2129.

Loizzo S, Pieri M, Ferri A, Carrì MT, Zona C, Fortuna A, and Vella S (2010b) Dynamic $\mathrm{NAD}(\mathrm{P}) \mathrm{H}$ post-synaptic autofluorescence signals for the assessment of mitochondrial function in a neurodegenerative disease: monitoring the primary motor cortex of G93A mice, an amyotrophic lateral sclerosis model. Mitochondrion 10:108-114.

Loizzo S, Vella S, Loizzo A, Fortuna A, Di Biase A, Salvati S, Frajese GV, Agrapart V, Ramirez Morales R, Spampinato S, et al. (2010c) Sexual dimorphic evolution of metabolic programming in non-genetic non-alimentary mild metabolic syndrome model in mice depends on feed-back mechanisms integrity for pro-opiomelanocortinderived endogenous substances. Peptides 31:1598-1605.

Lutz TA and Woods SC (2012) Overview of animal models of obesity. Curr Protoc Pharmacol; Chapter 5:Unit5.61. DOI: 10.1002/0471141755.ph0561s58.

Maccari S, Krugers HJ, Morley-Fletcher S, Szyf M, and Brunton PJ (2014) The consequences of early-life adversity: neurobiological, behavioural and epigenetic adaptations. J Neuroendocrinol 26:707-723.

Maccari S, Piazza PV, Kabbaj M, Barbazanges A, Simon H, and Le Moal M (1995) Adoption reverses the long-term impairment in glucocorticoid feedback induced by prenatal stress. J Neurosci 15:110-116.
McDowell J and Kitchen I (1987) Development of opioid systems: peptides, receptors and pharmacology. Brain Res 434:397-421.

McPherson RJ, Mascher-Denen M, and Juul SE (2009) Postnatal stress produces hyperglycemia in adult rats exposed to hypoxia-ischemia. Pediatr Res 66:278-282. Migliore M (2007) Stability and Plasticity of Ultradian Rhythms in a Scenery of Translational Models. Ph.D. thesis, University of Roma "La Sapienza," School of Doctorate in Psychobiology and Psychopharmacology, XXth Cycle [Ital], Rome, Italy

Moreira PI, Santos MS, Moreno AM, Seiça R, and Oliveira CR (2003) Increased vulnerability of brain mitochondria in diabetic (Goto-Kakizaki) rats with aging and amyloid-beta exposure. Diabetes 52:1449-1456.

Newsholme P, Gaudel C, and Krause M (2012) Mitochondria and diabetes. An in triguing pathogenetic role. Adv Exp Med Biol 942:235-247.

Oitzl MS, Champagne DL, van der Veen R, and de Kloet ER (2010) Brain development under stress: hypotheses of glucocorticoid actions revisited. Neurosci Biobehav Rev 34:853-866.

Perremans S, Randall JM, Rombouts G, Decuypere E, and Geers R (2001) Effect of whole-body vibration in the vertical axis on cortisol and adrenocorticotropic hormone levels in piglets. J Anim Sci 79:975-981.

Peters DA (1982) Prenatal stress: effects on brain biogenic amine and plasma corticosterone levels. Pharmacol Biochem Behav 17:721-725.

Pieretti S, d'Amore A, and Loizzo A (1991) Long-term changes induced by developmental handling on pain threshold: effects of morphine and naloxone. Behav Neurosci 105:215-218.

Ploj K and Nylander I (2003) Long-term effects on brain opioid and opioid receptor like-1 receptors after short periods of maternal separation in rats. Neurosci Lett 345:195-197.

Ploj K, Pham TM, Bergström L, Mohammed AH, Henriksson BG, and Nylander I (1999) Neonatal handling in rats induces long-term effects on dynorphin peptides. Neuropeptides 33:468-474.

Ploj K, Roman E, and Nylander I (2003) Long-term effects of short and long periods of maternal separation on brain opioid peptide levels in male Wistar rats. Neuropeptides 37:149-156.

Reagan LP (2012) Diabetes as a chronic metabolic stressor: causes, consequences and clinical complications. Exp Neurol 233:68-78.

Reyes TM (2012) High-fat diet alters the dopamine and opioid systems: effects across development. Int J Obes Suppl 2 (Suppl 2):S25-S28.

Rosenfeld P, van Eekelen JA, Levine S, and de Kloet ER (1993) Ontogeny of corticosteroid receptors in the brain. Cell Mol Neurobiol 13:295-319.

Selye H (1976) Forty years of stress research: principal remaining problems and misconceptions. Can Med Assoc J 115:53-56.

Shonkoff JP and Garner AS; Committee on Psychosocial Aspects of Child and Family Health; Committee on Early Childhood, Adoption, and Dependent Care; Section on Developmental and Behavioral Pediatrics (2012) The lifelong effects of early childhood adversity and toxic stress. Pediatrics 129:e232-e246.

Spampinato S, Canossa M, Carboni L, Campana G, Leanza G, and Ferri S (1994) Inhibition of proopiomelanocortin expression by an oligodeoxynucleotide complementary to beta-endorphin mRNA. Proc Natl Acad Sci USA 91:8072-8076.

Takahashi LK, Kalin NH, Barksdale CM, Vanden Burgt JA, and Brownfield MS (1988) Stressor controllability during pregnancy influences pituitary-adrenal hormone concentrations and analgesic responsiveness in offspring. Physiol Behav 42 $323-329$

Thaler JP, Yi CX, Schur EA, Guyenet SJ, Hwang BH, Dietrich MO, Zhao X, Sarruf DA, Izgur V, Maravilla KR, et al. (2012) Obesity is associated with hypothalamic injury in rodents and humans. J Clin Invest 122:153-162.

Thomas C, Hyppönen E, and Power C (2008) Obesity and type 2 diabetes risk in midadult life: the role of childhood adversity. Pediatrics 121:e1240-e1249.

Vale W, Spiees J, Rivier C, and Rivier J (1981) Characterization of a 41-residue ovine hypothalamic peptide that simulates the secretion of corticotropin and $\beta$-endorphin. Science 231:1394-1397.

Valenzuela CA, Castillo VA, Aguirre CA, Ronco AM, and Llanos MN (2011) The CB receptor antagonist SR141716A reverses adult male mice overweight and metabolic alterations induced by early stress. Obesity (Silver Spring) 19:29-35.

van Abeelen AF, Elias SG, Bossuyt PM, Grobbee DE, van der Schouw YT, Roseboom TJ, and Uiterwaal CS (2012) Famine exposure in the young and the risk of type 2 diabetes in adulthood. Diabetes 61:2255-2260.

van Donkelaar EL, Vaessen KR, Pawluski JL, Sierksma AS, Blokland A, Cañete R, and Steinbusch HW (2014) Long-term corticosterone exposure decreases insulin sensitivity and induces depressive-like behaviour in the $\mathrm{C} 57 \mathrm{BL} / 6 \mathrm{NCrl}$ mouse. PLOS ONE 9:e106960.

Vargas J, Junco M, Gomez C, and Lajud N (2016) Early life stress increases metabolic risk, HPA axis reactivity, and depressive-like behavior when combined with postweaning social isolation in rats. PLoS One 11:e0162665.

Vetulani J (2013) Early maternal separation: a rodent model of depression and a prevailing human condition. Pharmacol Rep 65:1451-1461.

Weininger O (1954) Physiological damage under emotional stress as a function of early experience. Science 119:285-286.

Address correspondence to: Stefano Loizzo, National Center for Global Health, Istituto Superiore di Sanità, via Regina Elena 299, 00161 Roma, Italy. E-mail: stefano.loizzo@iss.it 